\title{
Quantifying the top-down effects of grazers on a rocky shore: selective grazing and the potential for competition
}

\author{
Diana E. LaScala-Gruenewald ${ }^{1, *}$, Luke P. Miller ${ }^{1,4}$, Matthew E. S. Bracken ${ }^{2}$, \\ Bengt J. Allen ${ }^{3}$, Mark W. Denny ${ }^{1}$ \\ ${ }^{1}$ Hopkins Marine Station, Stanford University, Pacific Grove, CA 93950, USA \\ ${ }^{2}$ Department of Ecology and Evolutionary Biology, University of California Irvine, Irvine, CA 92697, USA \\ ${ }^{3}$ Department of Biological Sciences, California State University Long Beach, Long Beach, CA 90840, USA \\ ${ }^{4}$ Present address: Department of Biological Sciences, San Jose State University, San Jose, CA 95192, USA
}

\begin{abstract}
The effect of grazers on the diversity, distribution, and composition of their principal food source has rarely been described for the high intertidal zone of rocky shores, a model system for studying the potential effects of climate change. Along rocky, wave-swept shores in central California, the microphytobenthos (MPB) supports diverse assemblages of limpets and littorine snails, which, at current benign temperatures, could potentially partition food resources in a complementary fashion, thereby enhancing secondary productivity. Two limpet species in particular, Lottia scabra and L. austrodigitalis, may partition components of the MPB, and are likely to affect the composition of the MPB on which they graze. In this study, we describe the composition, nutritional value (C:N ratio), and fluorescence (an index of chlorophyll density) of ungrazed, L. scabragrazed and $L$. austrodigitalis-grazed MPB, each as a function of temperature. Fluorescence decreased with increased average daily maximum temperature for ungrazed MPB, but temperature had no discernible effects on either fluorescence or the composition of the MPB of grazed assemblages. L. austrodigitalis and L. scabra did not partition the MPB, and did not exhibit complementarity. Both species exhibited an ordered grazing scheme, in which limpets grazed down certain components of the MPB before others, and grazing increased the C:N ratio of the MPB, decreasing its nutritional value. Taken together, these results suggest that $L$. austrodigitalis and L. scabra may experience increased competition as warming temperatures reduce the available MPB.
\end{abstract}

KEY WORDS: Selective grazing - Intertidal zone - Biofilm - Microalgae - Microphytobenthos · Lottia $\cdot$ Limpets

\section{INTRODUCTION}

The distribution and diversity of primary producers play a major role in structuring communities. In terrestrial environments, plant assemblages and the biological and physical factors that determine their structure have been extensively studied (e.g. Harper 1977, Tilman 1988). The diversity, distribution and abundance of plant species affect a number of ecosystem processes that include productivity (Naeem et

${ }^{*}$ Corresponding author: dianalg@stanford.edu al. 1994, Tilman et al. 1996, Hector et al. 1999, Cardinale et al. 2007), functional stability (McNaughton 1977), the distribution and abundance of consumers (MacArthur \& Pianka 1966, Tahvanainen \& Root 1972) and resistance to invasive species (Fargione \& Tilman 2005, but see Levine \& D'Antonio 1999).

Numerous studies have examined the effects of intertidal grazers on the structure of macroalgal assemblages in the wave-swept, rocky intertidal zone, a model system for experimental ecology (see

(C) The authors 2016. Open Access under Creative Commons by Attribution Licence. Use, distribution and reproduction are unrestricted. Authors and original publication must be credited. 
Underwood 1979, Coleman et al. 2006 and Poore et al. 2012 for relevant syntheses; Dayton 1975, Littler \& Littler 1984, Gee \& Warwick 1994, Williams et al. 2013, and Best et al. 2014 for specific examples). However, relatively few have investigated the role of grazing on the epilithic microphytobenthos (MPB) that dominates the upper intertidal environment (but see Castenholz 1961, Nicotri 1977, Underwood 1984b and Underwood \& Murphy 2008), and the composition and distribution of the MPB in the upper intertidal environment has yet to be described at scales relevant to intertidal grazers (Seuront et al. 2007).

The intertidal MPB is composed of a diverse assemblage of organisms, including cyanobacteria, diatoms, macroalgal spores, germlings and juveniles and invertebrate larvae, all embedded in an extracellular matrix (Wahl 1989, Underwood 1984a, Davey \& O'Toole 2000). The MPB coats all hard surfaces submerged in water (Sekar et al. 2004), and extends to the top of the splash zone in the intertidal environment (Ricketts et al. 1968). In the upper intertidal zone, where the MPB is the only source of benthic primary productivity, it supports a diverse assemblage of limpets and littorine snails (Ricketts et al. 1968). However, the composition and distribution of components within the MPB, the potential for partitioning of these components by grazers, and the feedbacks between top-down consumption by grazers and bottom-up availability of nutrients in the MPB remain largely unknown.

In diverse terrestrial plant assemblages, niche partitioning can reduce interspecific competition, resulting in enhanced primary productivity relative to the performance of the most productive single-species assemblage (Tilman 2000, Naeem 2002, Hooper et al. 2005, Cardinale et al. 2011). This idea, called complementarity, is generalizable across trophic levels: increased predator diversity is also associated with higher rates of prey capture due to resource partitioning (Ives et al. 2004, Byrnes et al. 2006, Griffin et al. 2008). Although early studies linking biodiversity to ecosystem functioning highlighted the role of complementarity in temperate grassland assemblages, it also underpins relationships between diversity and productivity in intertidal systems (Griffin et al. 2008, Byrnes \& Stachowicz 2009, Cardinale et al. 2011, Bracken \& Williams 2013). For example, Griffin et al. (2008) used a factorial mesocosm experiment to explore how the species richness of prey assemblages affects the rate of prey consumption by 3 species of intertidal crabs. They found that, due to complementarity, all species of crabs ingested more food per individual when their prey was in polyculture than in any single monoculture. Through complementarity, diverse assemblages may also show increased resistance to the effects of climate change (Loreau et al. 2001): if resources become more scarce (as a result of increasing temperature, for instance), organisms that partition resources are more likely to survive and thrive. If upper intertidal grazers are complementary in their consumption of components of the MPB, it may have implications for how those species coexist now, and how they will be influenced by future climate shifts.

Nicotri (1977) measured the effects of foraging by the intertidal limpets Lottia pelta, Lottia strigatella and Lottia scutum and the littorine snail Littorina scutulata on MPB and observed that niche partitioning did not occur. She used transmitted light and scanning electron microscopy to determine that these 4 species grazed statistically indistinguishable quantities of the same species of cyanobacteria and diatoms from the MPB. However, her study organisms typically exist in different microhabitats, and thus may not always have been in direct competition for food resources. In addition, all 4 gastropod species supplement their diets with macroalgae, and so may not have experienced evolutionary pressure to specialize on the MPB. Similarly, Hawkins et al. (1989) examined 3 European gastropods, Gibbula umbilicalis, Littorina littorea and Patella vulgata, and found that their diets were indistinguishable despite differences in radular structure and feeding movements. But again, these species overlap only in a subset of locations across wide geographic ranges (Hawkins et al. 1989), and G. umbilicalis and $L$. littorea supplement their diets with detritus and macroalgae, respectively. Organisms that specialize entirely on the MPB and share the same microhabitat may be more likely to exhibit niche partitioning, and thus complementarity.

Recently, strong evidence has emerged that 3 intertidal gastropod species native to Italy may exhibit complementarity through resource partitioning (Sanz-Lázaro et al. 2015). These authors manipulated the density and richness of 2 limpet species (Patella ulyssiponensis and P. rustica) and one topshell (Porchus turbinatus) and observed the effects on the photosynthetic efficiency and photosynthetic biomass of the MPB. These gastropods share the same microhabitat in the intertidal environment, and they specialize on microalgae as their primary food resource. When two of these species grazed in concert, the photosynthetic efficiency of the MPB significantly increased while photosynthetic biomass did not, suggesting complementarity via resource partitioning. However, these effects were not additive: all 
3 species grazing together reduced photosynthetic efficiency back to levels typical of individual grazers.

Along the central coast of California, 2 limpet species, Lottia scabra Gould and Lottia austrodigitalis Murphy, share the upper intertidal habitat, living above the Mytilus californianus mussel zone and often beyond the upper extent of the macroalga Endocladia muricata (Wolcott 1973). They share this habitat with small barnacles (Chthamalus spp.) and a variety of littorine snails (Littorina spp.) (Ricketts et al. 1968). Both L. scabra and L. austrodigitalis live on vertical rock surfaces, although $L$. scabra can also be found on horizontal surfaces (Collins 1976, Hahn \& Denny 1989). Both species forage for microalgae twice per day during high tides, and exhibit a general dietary preference for diatoms (Nicotri 1977).

Previous research suggests that $L$. austrodigitalis and L. scabra are in direct competition for at least some food resources, and this competition could be driven by several factors. Haven (1973) observed that when $L$. austrodigitalis were excluded from a plot containing $L$. scabra in the intertidal zone at Hopkins Marine Station (HMS) in Pacific Grove, California, the density of the MPB increased, as did L. scabra growth rates. This result provides evidence that at least some portion of the MPB is a shared resource between the 2 species. However, it does not exclude the possibility that there are other components of the MPB that may be partitioned between $L$. austrodigitalis and L. scabra.

Food quality might also drive competition between L. austrodigitalis and L. scabra. Gastropod grazers, including limpets, are frequently selective in their preferences for intertidal algae (Della Santina et al. 1993, Bracken \& Low 2012). Often, the preferred species are those with higher internal nitrogen concentrations or lower carbon-to-nitrogen (C:N) ratios (Pedersen \& Borum 1996, Bracken et al. 2011, Bracken et al. 2014). This preference for higher nitrogen food sources is consistent with limitation of gastropod abundance and growth by nitrogen availability (Nielsen 2001, Sommer 2001). Differences between the C:N ratios of MPB grazed by $L$. austrodigitalis and $L$. scabra would suggest that they are targeting different food resources.

Lastly, temperature may influence the intensity of competition between these 2 Lottia species by reducing the availability, composition, or quality of an already limited food resource. Dark-adapted fluorescence of intertidal MPB can be used as a proxy for chlorophyll a density and is known to decrease as temperature increases (Miller et al. 2015). This suggests that less food is available to epilithic grazers like limpets when rock surface temperatures are high. Additionally, temperature may affect the composition and quality of the MPB. For example, Jackson et al. (2010) found that intertidal MPB on an Australian subtropical beach contained fewer cyanobacteria than that on a temperate beach. Diatoms may also be less plentiful at higher temperatures; they tend to be more abundant lower on the shore (Castenholz 1961) and decrease with increasing insolation (Thompson et al. 2004). Because diatoms are a nitrogen-rich food source for intertidal grazers, an increase in temperature may lead to a reduction in food quality, as well as food availability.

In this study, we investigated the effects of limpet grazing on the composition and quality of the upper intertidal MPB. Specifically, we asked 4 questions: (1) How does temperature influence the density and quality of the MPB? (2) How do L. austrodigitalis and $L$. scabra affect the density and composition of the MPB? (3) Do L. scabra and L. austrodigitalis exhibit complementarity by partitioning components of the MPB during grazing? (4) How does grazing by L. austrodigitalis and $L$. scabra affect the nutritional quality of the MPB? To answer these questions, we examined the dark-adapted fluorescence and C:N ratio (an index of food quality) of MPB as a function of average maximum daily temperature of the substratum. We also compared the dark-adapted fluorescence and composition of MPB that had not been grazed with MPB that had been grazed by L. scabra, MPB that had been grazed by $L$. austrodigitalis, and MPB that had been grazed by the natural suite of upper intertidal gastropods. Lastly, we quantified the percent cover of morphotypes in the MPB from each grazing treatment, and compared the results among treatments. We expected that increased temperatures and limpet grazing would decrease dark-adapted fluorescence values, change the composition of the MPB, and increase the C:N ratio. Additionally, if resource partitioning was occurring at the microscopic level, we expected that the composition of the L. scabragrazed MPB would differ from that of the L. austrodigitalis-grazed MPB.

\section{MATERIALS AND METHODS}

\section{Field experiment}

We selected 6 vertically-oriented field sites in the rocky, wave-swept intertidal zone adjacent to HMS $\left(36.6217^{\circ} \mathrm{N}, 121.9043^{\circ} \mathrm{W}\right)$ in Monterey Bay, California, USA. Sites were between 3 and $35 \mathrm{~m}$ apart. At 
each site, we deployed 4 circular aluminum plates (10 $\mathrm{cm}$ in diameter, $12 \mathrm{~mm}$ thick) in horizontal transects at $1.7 \mathrm{~m}$ above mean lower low water (MLLW). The average diurnal tidal range at this site is $1.6 \mathrm{~m}$. We covered each plate with a thin layer of light gray rubber grip tape (Safety Walk Tape, 3M) to encourage microalgal growth. Each plate was attached to the granite substratum with a central bolt, and a cement pad was constructed beneath each plate to ensure good thermal contact with the underlying rock. At each site, one plate held 4 Lottia scabra and one held $4 \mathrm{~L}$. austrodigitalis. This density (500 limpets $\mathrm{m}^{-2}$ ) corresponded to that observed in limpetrich areas of the intertidal zone at HMS (Morelissen \& Harley 2007). Individuals of about $1 \mathrm{~cm}$ in shell length were selected for the experiment, and were corralled using $20 \mathrm{~mm}$ tall, stainless steel mesh fences $(5.5 \mathrm{~mm}$ square mesh size). These fences deterred most limpets from leaving the plates, but an average of $0.11 \pm 0.15 \mathrm{~L}$. scabra and $1.31 \pm 0.94 \mathrm{~L}$. austrodigitalis were still lost per month. A third plate at each site had an identical fence and served as a grazer exclusion control, while the fourth plate lacked a fence altogether and allowed access by grazers living on the neighboring natural rock surface. We deployed the plates in June of 2013, and they remained in the field through December of that year. Fences were cleared of any macroalgal growth in the late fall.

In Monterey Bay, L. austrodigitalis overlaps with a cryptic congener, L. digitalis Rathke. The 2 species can be reliably identified only through genetic methods. However, prior research at our field site suggests that $L$. austrodigitalis are most commonly found on vertical rocky surfaces, while $L$. digitalis is associated with the micro-environment provided by the gooseneck barnacle Pollicipes polymerus Sowerby (Crummett \& Eernisse 2007). More recent work has also shown that $L$. austrodigitalis makes up 88 to $89 \%$ of the cryptic species pair in high shore habitats at HMS (Dong et al. 2008, Dong \& Somero 2009), where our limpets were collected. We refer to $L$. austrodigitalis throughout the remainder of this study, acknowledging that a small percentage of our organisms may in fact be L. digitalis.

\section{Temperature}

Temperature measurements were obtained for each plate using iButton temperature dataloggers $\left(0.5^{\circ} \mathrm{C}\right.$ resolution, Maxim Integrated, San Jose, CA, USA). We machined a circular pocket in the back of each plate to hold the iButton. Each iButton was coated in a thin layer of paraffin wax for waterproofing, and all iButtons were calibrated in a waterbath prior to deployment. The iButtons recorded temperature every $12 \mathrm{~min}$, and we downloaded the data every 2 wk.

At the conclusion of the experiment, the average maximum daily temperature for December 2013 was calculated for each plate. We evaluated whether these temperatures were consistent across sites using ANOVA and Tukey's HSD test for multiple comparisons. Because our grazing treatments were not likely to influence the temperature of the plates, we used the 4 plates at each site as replicates for this analysis. Visual checks were performed to ensure that model assumptions of normality and equal variances were met. Analyses were carried out in MATLAB 2014a (MathWorks).

\section{Dark-adapted fluorescence}

We surveyed plates on July 10, August 6, September 6, October 6, November 6 and December 1, 2013 during favorable tides and wave conditions. During each survey, we replaced any limpets lost during the previous month and measured the density of the MPB. The density of the MPB was approximated using a PAM fluorometer (DivingPAM, Walz). We took 6 dark-adapted fluorescence measurements haphazardly on each plate during night-time low tides. The dark-adapted fluorescence value $\left(F_{0}\right)$ from the fluorometer serves as a proxy for the chlorophyll a density of the MPB (Barranguet et al. 2000, Honeywill et al. 2002, Serôdio et al. 2008). The tip of the fiber-optic measuring head of the fluorometer was fitted with a $10 \mathrm{~mm}$ spacer to maintain a fixed distance from the experimental plate, and the opening covered an area of $53 \mathrm{~mm}^{2}$. The tip was held in place at each measurement site until the $F_{0}$ value stabilized (typically 3-5 s) before recording a value, as recommended by the manufacturer. Because changes in surface moisture can affect $F_{0}$ values (Maggi et al. 2013), we restricted sampling to periods when the plates were moist but not actively splashed or submerged by the tide.

Two-factor ANOVA and Tukey's HSD test for multiple comparisons were used to compare darkadapted fluorescence values for December 2013 across sites and grazing treatments. Due to our unreplicated block experimental design, we could not test for an interaction between these 2 factors 
(Underwood 1997). To minimize the possibility of interactions arising from spatial differences in temperature, we eliminated site 6 , which was significantly warmer than the other sites, from our ANOVA. However, temperature and dark-adapted fluorescence are known to be negatively correlated (Miller et al. 2015), so we ran an additional analysis of covariance to determine whether the relationship between temperature and dark-adapted fluorescence was likely influenced by grazing treatment. The data from site 6 were included in this test to provide a larger temperature range. Visual checks were performed to ensure that model assumptions of normality and equal variances were met. Analyses were carried out in MATLAB 2014a.

\section{Scanning electron microscopy}

After plates were removed from the field, we haphazardly selected and cut 3 samples $\left(1 \mathrm{~cm}^{2}\right.$ each) of rubber tape from each plate. The samples were soaked in a $2.5 \%$ gluteraldehyde solution for 15 to 45 min to preserve cell shape, washed in phosphatebuffered solution ( $\mathrm{pH}$ 7.9) for $15 \mathrm{~min}$, rinsed in de-ionized water and air dried. Samples were then gold-coated using a SPI-MODULE sputter coater (Structure Probe), and viewed under a scanning electron microscope (SEM; FEI Quanta 200, hv $=25 \mathrm{kV}$, spot size $=4 \mathrm{~nm}$ ) at a magnification of 300 $\times$. This magnification resulted in a $0.159 \mathrm{~mm}^{2}$ field of view. Nine fields were chosen haphazardly from each sample and photographed, for a total of 648 images (162 images per treatment).

\section{Identification and quantification of morphotypes}

We processed each image using the photoQuad image analysis program (www.mar.aegean.gr/ sonarlab/photoquad/index.php). A spatially stratified, random field of 50 points was overlaid on the entire image, from which percent cover of the components of the MPB was calculated. Points that fell in areas that were not in focus were excluded from the analysis. We chose the magnification of $300 \times$ to visualize diatoms and cyanobacteria, which are the components of the MPB thought to be the preferred food sources for Lottia spp. (Castenholz 1961, Haven 1973, Nicotri 1977, Connor \& Quinn 1984). This resolution did not allow us to identify each organism at the species level. Instead, components of the MPB were classified by morphotypes, which took into account general shape, size and other features observable at $300 \times$ (Fig. 1). These morphotypes were based on the organisms described, identified and pictured by Nagarkar \& Williams (1997) and Hawkins et al. (1989). Morphotypes 1 to 5 were long, narrow organisms and were classified as filamentous cyanobacteria. Morphotypes 6 to 12 were smaller, boxy or rod-like organisms and were classified as diatoms. Organisms described as morphotype 13 formed encrusting mats with individual components that were impossible to distinguish at 300x. Morphotype 14 consisted of small encrusting organisms, but they grew in a characteristic diamond pattern. This pattern did not correspond in scale to the topographical features of the rubber grip tape or the radulae of $L$. scabra or L. austrodigitalis. Morphotype 15 comprised small, round organisms that were classified as coccoidal cyanobacteria. Lastly, morphotype 16 described any other organism observed, while morphotype 17 indicated empty rubber grip tape.

From the random field of 50 points, percent cover of each morphotype was calculated as the number of points covering a particular morphotype divided by the total number of points (usually 50, minus any points not scored due to focus issues). Percent cover of organism type (filamentous cyanobacteria, diatoms, encrusting organisms or coccoidal cyanobacteria) was also calculated. We averaged percent cover of morphotypes and organism types within each plate $(n=27)$ and we calculated average percent cover of morphotypes and organism types for each grazing treatment across sites $(\mathrm{n}=6)$. To determine (1) how grazing by L. scabra and L. austrodigitalis affected MPB composition, and (2) whether the 2 species were partitioning the MPB, we used PRIMER v6 software (www.primer-e.com/) to generate MDS plots to visualize organism- and morphotype-level variation in assemblage structure among grazing treatments. Analysis of similarity (ANOSIM) was used to assess the relative size of these differences (Clarke \& Warwick 2001). Because untransformed data place heavy emphasis on similarities in abundant organisms between assemblages (Clarke \& Warwick 2001), square-root and fourth-root transformations of the raw data were also performed. These transformations put increasing emphasis on similarities in rare organisms between assemblages. Finally, the top contributors to differences in MPB composition were identified using similarity percentage tests (SIMPER; Clarke \& Warwick 2001). 

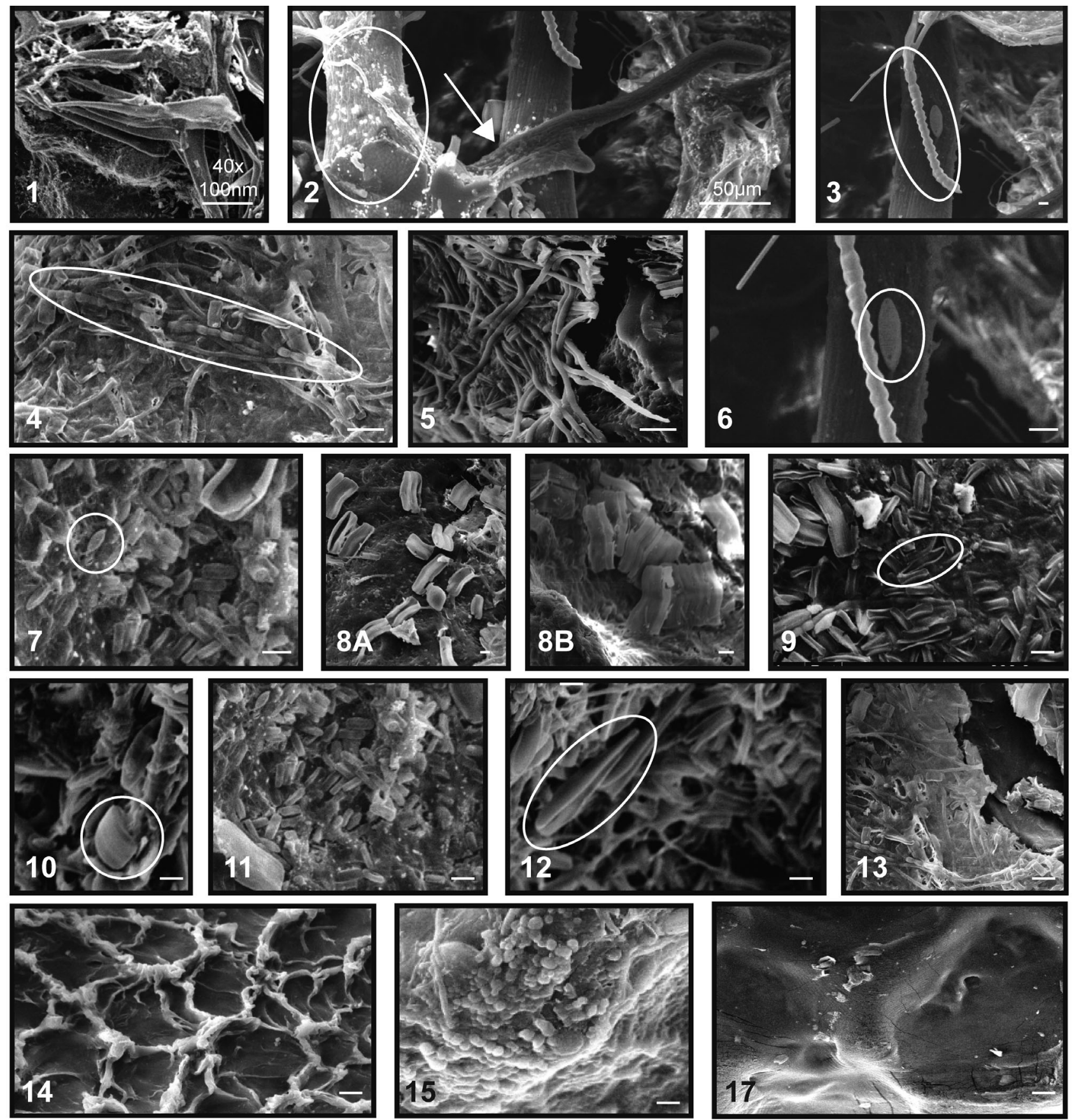

Filamentous cyanobacteria:

1 - 800nm x 150nm

2 - $200 \mu \mathrm{m} \times 50 \mu \mathrm{m}$, includes branches (see arrow)

3 - bead diameter $10 \mu \mathrm{m}$

4 - bead diameter $<10 \mu \mathrm{m}$

5 - width $<7 \mu \mathrm{m}$

Diatoms:

6 - Pointed, $30 \mu \mathrm{m} \times 10 \mu \mathrm{m}$
7 - Pointed, $10 \mu \mathrm{m} \times 5 \mu \mathrm{m}$

$8 \mathrm{~A}$ - Boxy, $40 \mu \mathrm{m} \times 20 \mu \mathrm{m}$

8B - Can form chains, as shown

9 - Can form chains, $25 \mu \mathrm{m} \times 7 \mu \mathrm{m}$

10 - Can form chains, $13 \mu \mathrm{m} \times 8 \mu \mathrm{m}$

11 - Less than $10 \mu \mathrm{m} \times 5 \mu \mathrm{m}$

12 - Tapered, length $70 \mu \mathrm{m}$

Encrusting Organisms:

13 - Encrusting, undefined shape
14 - Diamond pattern, length

30-60um

Coccoidal Cyanobacteria:

15 - Diameter $<5 \mu \mathrm{m}$

Non-Biological:

16 - Other, not shown

17 - Rubber grip tape (biofilm substrate)

Fig. 1. Descriptions and images of morphotypes observed in the MPB. Each morphotype is identified by a number (1-17), and is pictured at $300 \times$ unless otherwise indicated. Scale bars are $10 \mu \mathrm{m}$ unless otherwise indicated, circles highlight the specific organism being described and all measurements provided are approximate. The bottom panel includes each morphotype number, in addition to the organism's broader classification (filamentous cyanobacteria, diatom, encrusting organism or coccoidal cyanobacteria) and a summary of the shape and size details used to identify the organism 


\section{Carbon and nitrogen elemental analysis}

A second, larger field experiment was deployed from June 2014 through January of 2015. It was assembled as described above, except 6 replicate plates of 8 grazing treatments were placed at each field site: an ungrazed treatment, a natural-grazed treatment consisting of a cage-control half-fence, 3 L. scabra-grazed treatments with 4, 8 or twelve limpets, and $3 \mathrm{~L}$. austrodigitalis-grazed treatments with 4, 8 or twelve limpets. A subset of these plates with visually apparent MPB were used to evaluate the effects of limpet grazing on the nutritional content of the MPB.

Scrapings of the MPB were obtained from 34 ungrazed, 24 natural-grazed, 10 L. scabra-grazed and 9 L. austrodigitalis-grazed plates with sufficient MPB to permit sampling. To determine internal carbon and nitrogen concentrations, scrapings were dried to constant mass $\left(60^{\circ} \mathrm{C}\right.$ for $\left.72 \mathrm{~h}\right)$, ground to a fine powder in stainless steel microvials (Retsch Mixer Mill MM 400, Verder Scientific) and analyzed on a Flash 2000 Elemental Analyzer configured for analyses of $\mathrm{C}$ and $\mathrm{N}$ in organic samples (Thermo Fisher). Carbon-to-nitrogen $(\mathrm{C}: \mathrm{N})$ ratios were then calculated for each plate.

We compared a set of linear mixed effects models using likelihood ratio tests to determine whether grazing treatment and 2 covariates, log-transformed $F_{0}$ and average daily maximum temperature, or the interaction between these factors helped explain C:N ratios. C:N ratios were log-transformed to meet the assumption of normality in the residuals. Site (1 to 6) was included as a random factor to account for potential blocking effects. Due to the relatively small number of limpet-grazed plates with visually apparent MPB for the C:N analysis, the number of limpets per plate could not be included as a factor in our model. The number of plates sampled for each combination of fixed factors varied from 0 to 6 within each block. Analysis of deviance tests and Tukey's HSD tests were used to determine differences in $\mathrm{C}: \mathrm{N}$ ratios among grazing treatments. Analyses were carried out in R 3.2.5 (R Development Core Team 2016).

\section{Effects of limpet density}

Although each limpet-grazed plate was initially seeded with 4 limpets in the 2013 experiment, some animals either escaped from or fell off the plates each month. This prompted us to explore the effects of limpet loss on the composition of the MPB. We examined the relationships between the number of limpets remaining on a plate the month prior to plate recovery from the field (December 2013) and the percent cover of morphotypes at recovery using ANOVA and Tukey's HSD multiple comparisons test. Sample size was low for this test $\left(\mathrm{n}_{(0 \text { limpets })}=6\right.$, $\left.\mathrm{n}_{(2 \text { limpets })}=1, \mathrm{n}_{(3 \text { limpets })}=3, \mathrm{n}_{(4 \text { limpets })}=8\right)$. Additionally, we lacked full replication for both sites and grazing treatments, so contributions from, and interactions with, these factors could not be computed (Underwood 1997). Visual checks were performed to ensure that model assumptions of normality and equal variances were met. Analyses were carried out in MATLAB 2014a.

\section{RESULTS}

\section{Temperature}

The average maximum daily temperature on plates at site 6 (mean $\pm \mathrm{SE}=18.73 \pm 0.51^{\circ} \mathrm{C}$ ) was significantly higher than those at the other 5 sites (13.87 \pm $\left.0.03^{\circ} \mathrm{C}_{i} F_{5,15}=20.62, \mathrm{p}<0.001\right)$. To determine whether temperature might be influencing the composition of the MPB, we divided our ungrazed plates into cool samples (average maximum daily temperature $<14^{\circ} \mathrm{C}$ ) and warm samples (average maximum daily temperature $\geq 14^{\circ} \mathrm{C}$ ). An analysis of similarity was performed. We found no evidence of a difference between the composition of the MPB on warmer and cooler ungrazed plates $(\mathrm{R}=-0.179, \mathrm{p}=0.667)$, although our sample size for this test was small ( $\mathrm{n}=4$ cool plates, $\mathrm{n}=2$ warm plates). Additionally, the average difference in daily maximum temperature between warm and cool plates was only $3^{\circ} \mathrm{C}$.

\section{Dark-adapted fluorescence}

$F_{0}$, our proxy for microalgal density, was significantly higher for the ungrazed treatment than for the natural-grazed, Lottia scabra-grazed and L. austrodigitalis-grazed treatments $\left(F_{3,16}=23.10, \mathrm{p}<0.001\right)$ (Fig. 2, Table S1 in the Supplement at www.intres.com/articles/suppl/m553p049_supp.pdf). Site was not a significant factor in this analysis $\left(F_{4,15}=1.19, \mathrm{p}=\right.$ 0.365). $F_{0}$ was affected by an interaction between grazing treatment and average maximum daily temperature $\left(F_{3,16}=9.47, \mathrm{p}<0.001\right) ; F_{0}$ was inversely proportional to temperature for the ungrazed treatment (slope of linear model $=-27.23^{\circ} \mathrm{C}^{-1}$ ), but the 2 variables were uncorrelated for the 3 grazed treatments 


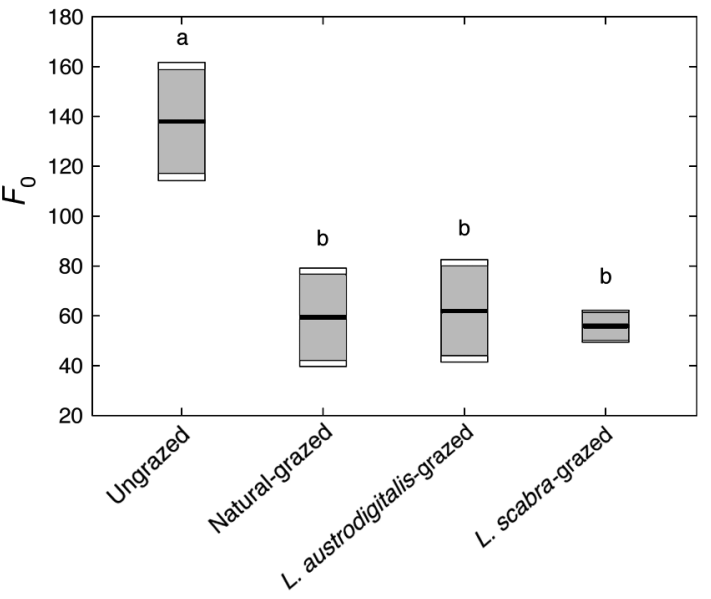

Fig. 2. Effect of grazing treatment on $F_{0}$. The L. scabragrazed, L. austrodigitalis-grazed and natural-grazed treatments exhibited decreased chlorophyll density $\left(F_{0}=55.2 \pm\right.$ $5.2)$ relative to the ungrazed treatment $\left(F_{0}=117.5 \pm 22.2\right)$ during the month prior to SEM sample collection. Black lines indicate the mean values for each treatment, grey rectangles represent one standard deviation and white rectangles represent $95 \%$ confidence intervals ( $\mathrm{n}=6$ for all treatments). Letters indicate significantly different $F_{0}$ values, as determined by Tukey's HSD test for multiple comparisons

(Fig. 3, Table S2). This trend was driven by the warm site, site 6 . When site 6 was excluded from the analysis, grazing treatment did not significantly affect the relationship between temperature and $F_{0}\left(F_{3,12}=0.51\right.$, $\mathrm{p}=0.682$ ). The main effect of grazing treatment was still significant $\left(F_{3,12}=24.64, \mathrm{p}<0.001\right)$, however, and the average $F_{0}$ value on ungrazed plates remained significantly higher than that on grazed plates.

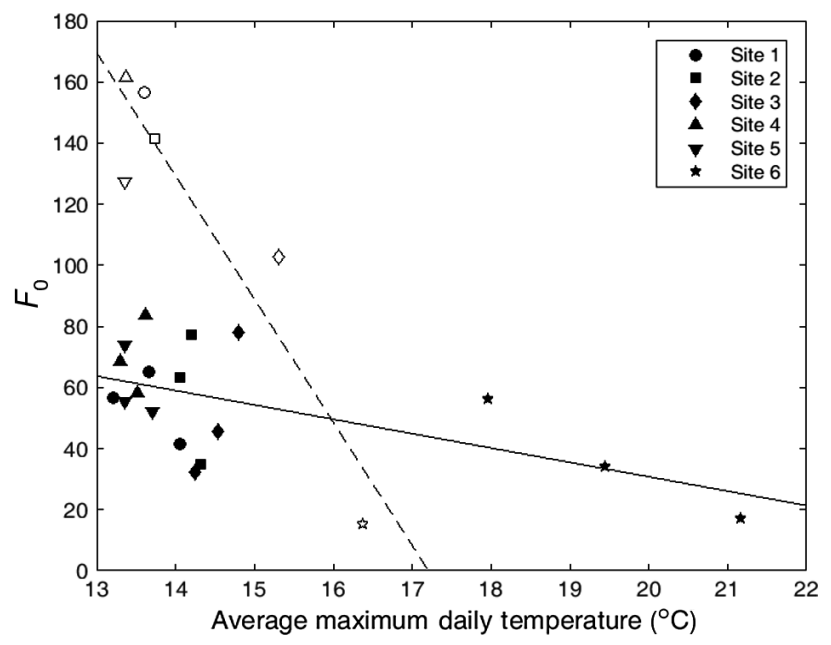

Fig. 3. Regressions of $F_{0}$ on average maximum daily temperature for different treatments. The negative relationship was significantly steeper on ungrazed plates than on grazed plates. White symbols and dashed line: ungrazed plates; black symbols and solid line: grazed plates

\section{Organism-level assemblage data}

Analysis of similarity on untransformed data indicated that the MPB of the ungrazed treatment was significantly different from that of either the $L$. scabra-grazed treatment $(\mathrm{R}=0.284, \mathrm{p}=0.035)$ or the $L$. austrodigitalis-grazed treatment $(\mathrm{R}=0.247, \mathrm{p}$ = 0.048) (Fig. 4). Additionally, the MPB of the natural-grazed treatment was different from that of the L. scabra-grazed treatment $(\mathrm{R}=0.185, \mathrm{p}=0.041)$, but not from the other treatments. No significant difference was observed between the L. scabra and L. austrodigitalis-grazed treatments $(\mathrm{R}=0.117, \mathrm{p}=$ 0.123). As increasing emphasis was placed on the presence or absence of rare organisms by squareroot and fourth-root transforming the data, the ungrazed MPB differed more from the 3 grazed MPBs (Table 1).

Similarity percentage tests indicated that differences between the ungrazed MPB and the $L$. scabra-grazed MPB were driven by percent cover of filamentous cyanobacteria, diatoms and encrusting organisms. On average, the ungrazed MPB exhibited a higher percent cover of filamentous cyanobacteria and diatoms, and a lower percent cover of encrusting organisms (Table 2). Similar differences were identified between the ungrazed MPB and the L. austrodigitalis-grazed MPB, except these differences were also driven by percent cover of coccoidal cyanobacteria, which was more abundant in the L. austrodigitalis-grazed MPB. Differences between the natural-grazed MPB and the L. scabra-grazed MPB were driven by filamentous and coccoidal cyanobacteria. The former assemblage exhibited higher percent cover of both organisms relative to the latter.

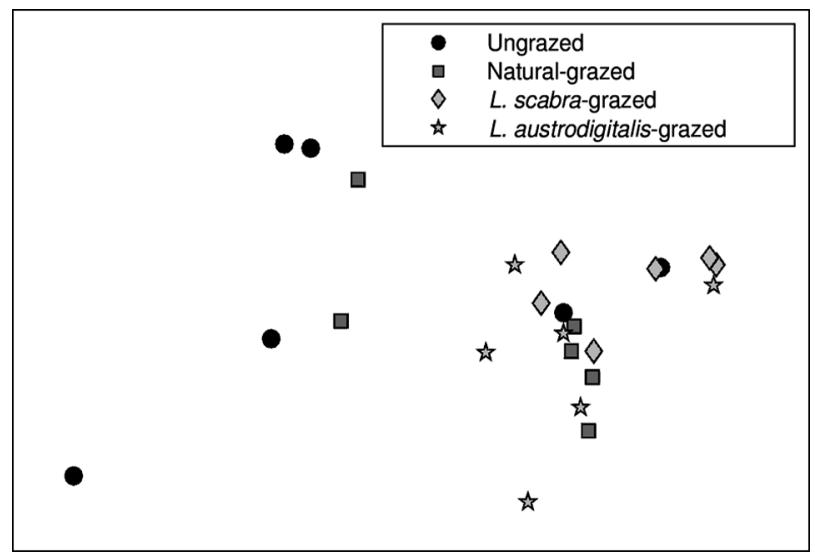

Fig. 4. MDS plot showing variation in assemblage structure of MPB among grazing treatments at the organism level 
Table 1. MPB composition data at 3 levels of transformation. Analysis of similarity was used to determine significant differences inthe composition of the MPB across grazing treatments when the data underwent no transformation, a square-root transormation, and a fourth-root transformation. Data from both the organism-level analysis and the morphotype-level analysis are shown. Significant p-values are in bold type; associated R-values are in parentheses

\begin{tabular}{|c|c|c|c|c|c|c|}
\hline \multirow{2}{*}{ Treatments being compared } & \multicolumn{3}{|c|}{ _ Organism level } & \multicolumn{3}{|c|}{ Morphotype level } \\
\hline & No transformation & Square-root & Fourth-root & No transformation & Square-root & Fourth-root \\
\hline Ungrazed and Natural & $\begin{array}{c}0.093 \\
(-0.127)\end{array}$ & $\begin{array}{r}0.087 \\
(-0.159)\end{array}$ & $\begin{array}{c}0.093 \\
(-0.144)\end{array}$ & $\begin{array}{c}0.301 \\
(-0.026)\end{array}$ & $\begin{array}{r}\mathbf{0 . 0 3 5} \\
(-0.281)\end{array}$ & $\begin{array}{c}\mathbf{0 . 0 1 1} \\
(-0.393)\end{array}$ \\
\hline Ungrazed and L. scabra & $\begin{array}{c}\mathbf{0 . 0 3 5} \\
(-0.284)\end{array}$ & $\begin{array}{c}\mathbf{0 . 0 2 4} \\
(-0.306)\end{array}$ & $\begin{array}{c}\mathbf{0 . 0 1 5} \\
(-0.294)\end{array}$ & $\begin{array}{c}\mathbf{0 . 0 0 2} \\
(-0.559)\end{array}$ & $\begin{array}{c}\mathbf{0 . 0 0 2} \\
(-0.711)\end{array}$ & $\begin{array}{c}\mathbf{0 . 0 0 2} \\
(-0.661)\end{array}$ \\
\hline Ungrazed and $L$. austrodigitalis & $\begin{array}{c}\mathbf{0 . 0 4 8} \\
(-0.247)\end{array}$ & $\begin{array}{c}\mathbf{0 . 0 2 8} \\
(-0.285)\end{array}$ & $\begin{array}{c}\mathbf{0 . 0 2 2} \\
(-0.233)\end{array}$ & $\begin{array}{c}\mathbf{0 . 0 0 6} \\
(-0.274)\end{array}$ & $\begin{array}{c}\mathbf{0 . 0 0 4} \\
(-0.515)\end{array}$ & $\begin{array}{c}\mathbf{0 . 0 0 2} \\
(-0.631)\end{array}$ \\
\hline Natural and L. scabra & $\begin{array}{c}\mathbf{0 . 0 4 1} \\
(-0.185)\end{array}$ & $\begin{array}{c}0.069 \\
(-0.191)\end{array}$ & $\begin{array}{r}0.067 \\
(-0.25)\end{array}$ & $\begin{array}{r}\mathbf{0 . 0 3 9} \\
(-0.293)\end{array}$ & $\begin{array}{c}\mathbf{0 . 0 2 6} \\
(-0.307)\end{array}$ & $\begin{array}{r}0.169 \\
(-0.122)\end{array}$ \\
\hline Natural and $L$. austrodigitalis & $\begin{array}{c}0.766 \\
(-0.068)\end{array}$ & $\begin{array}{c}0.814 \\
(-0.076)\end{array}$ & $\begin{array}{c}0.461 \\
(-0.004)\end{array}$ & $\begin{array}{c}0.229 \\
(-0.078)\end{array}$ & $\begin{array}{c}0.331 \\
(-0.026)\end{array}$ & $\begin{array}{c}0.297 \\
(-0.044)\end{array}$ \\
\hline L. scabra and L. austrodigitalis & $\begin{array}{c}0.123 \\
(-0.117)\end{array}$ & $\begin{array}{c}0.249 \\
(-0.069)\end{array}$ & $\begin{array}{c}0.372 \\
(-0.002)\end{array}$ & $\begin{array}{c}0.652 \\
(-0.069)\end{array}$ & $\begin{array}{c}0.578 \\
(-0.044)\end{array}$ & $\begin{array}{c}0.645 \\
(-0.054)\end{array}$ \\
\hline
\end{tabular}

\section{Morphotype-level assemblage data}

Similar trends were exhibited at the morphotype level as those at the organism-level. The ungrazed treatment was significantly different from both the $L$. scabra-grazed treatment $(\mathrm{R}=0.559, \mathrm{p}=0.002)$ and the $L$. austrodigitalis-grazed treatment $(\mathrm{R}=0.274, \mathrm{p}=$ 0.006) when analyses were done on untransformed

Table 2. Comparison of percent cover of organisms and morphotypes across grazing treatments. Percent cover of organisms (filamentous cyanobacteria, encrusting organisms, coccoidal cyanobacteria and diatoms) and morphotypes (filamentous cyanobacteria 2 and 5, diatoms 8, 9 and 11, encrusting organisms 13 and 14 and coccoidal cyanobacteria 15) is shown for each treatment. Organisms that were relatively abundant in grazed treatments are in bold type, while those that were relatively scarce in grazed treatments are italicized

\begin{tabular}{|lrrrr|}
\hline & Ungrazed & Natural & \multicolumn{1}{c}{$\begin{array}{c}\text { L. } \\
\text { scabra }\end{array}$} & $\begin{array}{c}\text { L. austro- } \\
\text { digitalis }\end{array}$ \\
\hline Organism-level & & & & \\
Filamentous cyanobacteria & 20.83 & 16.00 & 9.83 & 12.83 \\
Encrusting organisms & $\mathbf{6 3 . 8 3}$ & $\mathbf{7 1 . 8 3}$ & $\mathbf{8 4 . 1 7}$ & $\mathbf{7 6 . 5 0}$ \\
Coccoidal cyanobacteria & 3.50 & 9.17 & 4.67 & 9.50 \\
Diatoms & 10.00 & 3.00 & - & 1.00 \\
Morphotype-level & & & & \\
2 & 1.60 & 0.02 & 0.05 & 0.02 \\
5 & 17.11 & 15.15 & 8.92 & 11.56 \\
8 & 1.68 & 0.83 & 0.14 & 0.12 \\
9 & 6.18 & 1.11 & 0.36 & 0.52 \\
11 & 2.10 & 0.65 & 0.74 & 0.19 \\
13 & 60.53 & 58.76 & 44.61 & 45.01 \\
14 & $\mathbf{3 . 0 9}$ & $\mathbf{1 2 . 8 3}$ & $\mathbf{3 9 . 0 5}$ & $\mathbf{3 2 . 2 1}$ \\
15 & 3.58 & 9.35 & 4.88 & 9.12 \\
\hline
\end{tabular}

data (Fig. 5). Once again, the natural-grazed treatment and the L. scabra-grazed treatment also differed $(\mathrm{R}=0.293, \mathrm{p}=0.039)$, although this difference became non-significant after transforming the data (Table 1). The specific morphotypes driving these differences in composition were identified. Limpetgrazed treatments exhibited lower percent cover in morphotypes 2 and 5 (cyanobacteria), 8, 9 and 11 (diatoms) and 13 (encrusting organisms), but higher percent cover in morphotype 14 (encrusting organisms) (Table 2).

\section{Evidence for resource partitioning}

Both the organism-level and morphotype-level data indicate no significant differences in composition between the MPB grazed by L. scabra and that grazed by L. austrodigitalis (Table $1 ; \mathrm{R}=$ $0.117, \mathrm{p}=0.123$ and $\mathrm{R}=-0.069, \mathrm{p}=$ 0.652, respectively). Emphasizing rare organisms by transforming the MPB composition data makes these communities appear more similar (Table 2). An MDS plot was generated using only $L$. scabra-grazed and L. austrodigitalisgrazed treatments that had the full quota of 4 limpets during the month prior to sample collection ( $\mathrm{n}=8$ out of 12 limpet-grazed plates); after controlling for limpet density, there was no sig- 


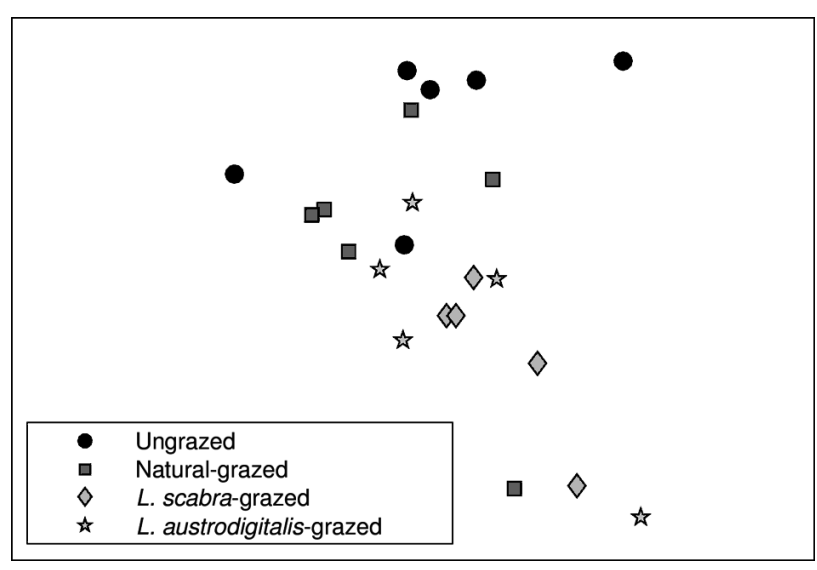

Fig. 5. MDS plot showing variation in assemblage structure of MPB among grazing treatments at the morphotype level

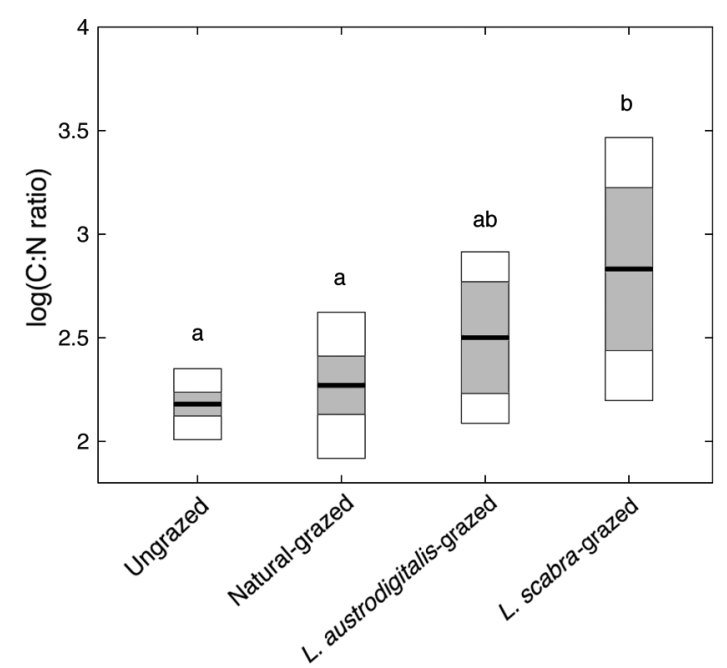

Fig. 6. Effects of grazing treatment on C:N ratio. Grazing by $L$. scabra significantly increased the $\log (\mathrm{C}: \mathrm{N})$ ratio of the $\operatorname{MPB}\left(F_{2,45}=12.98, \mathrm{p}<0.001\right)$. Black lines indicate the mean values for each treatment, grey rectangles represent one standard deviation and white rectangles represent $95 \%$ confidence intervals $\left(\mathrm{n}_{\text {ungrazed }}=34, \mathrm{n}_{L \text {. scabra-grazed }}=\right.$ $10, \mathrm{n}_{L}$. austrodigitalis-grazed $=9$ ). Letters indicate significantly different $\mathrm{C}: \mathrm{N}$ ratios as determined by Tukey's test for multiple comparisons

nificant difference between $L$. scabra and $L$. austrodigitalis-grazed plates $(\mathrm{R}=-0.031, \mathrm{p}=0.393)$.

\section{Nutrient concentrations and ratios}

The best-fit linear model describing trends in the log-transformed $\mathrm{C}: \mathrm{N}$ ratio data included no significant interactions between $\log$-transformed $F_{0}$, average daily maximum temperature or grazing treatment. Temperature was eliminated as a main effect as well. The variance due to the random effect of Site was estimated as 0.002 . C:N ratios were related to both $F_{0}$ and the grazing treatment $\left(\chi_{1}^{2}=8.1, \mathrm{p}<0.01\right.$ and $\chi_{1}^{2}=30.5, \mathrm{p}<0.001$, respectively). $\mathrm{C}: \mathrm{N}$ ratios were negatively related to increasing log-transformed $F_{0}$ values (slope $=-0.2 \pm 0.07$ ), while $L$. scabra-grazed plates were found to be significantly depleted in nitrogen $(\log \mathrm{C}: \mathrm{N}=2.83 \pm 0.2)$ relative to the ungrazed plates $(\log \mathrm{C}: \mathrm{N}=2.18 \pm 0.03, \mathrm{p}<0.001)$ and natural-grazed plates $(\log \mathrm{C}: \mathrm{N}=2.27 \pm 0.07, \mathrm{p}<$ 0.001) (Fig. 6). L. austrodigitalis-grazed plates, however, were not significantly different from the $L$. scabra-grazed, natural-grazed or ungrazed plates.

Because diatoms are believed to be the primary contributors to nitrogen in intertidal MPB, we additionally tested whether the ratio of diatoms to cyanobacteria differed among grazing treatments. We found that this ratio was significantly reduced in $L$. scabra-grazed and L. austrodigitalis-grazed MPB $\left(\mathrm{ANOVA} ; F_{3,20}=4.150, \mathrm{p}=0.019\right)$.

\section{Effects of limpet density}

Although each limpet-grazed plate was initially seeded with 4 limpets in the 2013 experiment, some animals either escaped from or fell off the plates each month. These animals were replaced during monthly surveys. The month prior to SEM sample collection (December 2013), no L. scabra were lost, but the $L$. austrodigitalis plates lost between 0 and 2 individuals, resulting in an average retention of $3.2 \pm 0.8$ limpets per plate (approximately 400 limpets $\mathrm{m}^{-2}$ ). Significant correlations were found between the number of limpets on the plates at the end of December 2013 and the percent cover of coccoidal cyanobacteria and encrusting organisms (Fig. 7). Percent cover of coccoidal cyanobacteria was highest at the intermediate densities of 2 or 3 limpets per plate $\left(F_{3,14}=6.52, \mathrm{p}=0.006\right)$. Percent cover of encrusting organisms was positively related to limpet density $\left(F_{10,12}=5.200, \mathrm{p}=0.046\right)$; however, at the morphotype level, morphotype 13 decreased with limpet density while morphotype 14 increased. $\left(F_{3,14}=1.6, \mathrm{p}=0.23\right.$ and $F_{3,14}=5.59, \mathrm{p}=0.01$ respectively). Filamentous cyanobacteria (morphotype 5) and diatoms (morphotypes 8 and 9) were present in relatively low percentages if any grazers were present, but these trends were not significantly correlated with the number of grazers $\left(F_{3,14}=1.48\right.$ and $\mathrm{p}=0.26, F_{3,14}=1.79$ and $\mathrm{p}=$ 0.19 , and $F_{3,14}=2.27$ and $\mathrm{p}=0.13$ respectively). Finally, during both the 2013 and 2014 experiments, significant negative correlations were found between $F_{0}$ and the number of limpets remaining on the 
Fig. 7. Effects of number of grazers on percent cover of selected morphotypes. Analysis of variance was used to determine the effects of number of grazers on percent cover of filamentous cyanobacteria 5, diatoms 8 and 9 , encrusting organisms 13 and 14, and coccoidal cyanobacteria 15. Black lines indicate the mean values for each treatment, grey rectangles represent one standard deviation and white rectangles represent $95 \%$ confidence intervals $\left(\mathrm{n}_{0}=6, \mathrm{n}_{2}=1, \mathrm{n}_{3}=3, \mathrm{n}_{4}=8\right)$. Letters indicate significantly different percent covers of morphotypes as determined by Tukey's HSD test for multiple comparisons
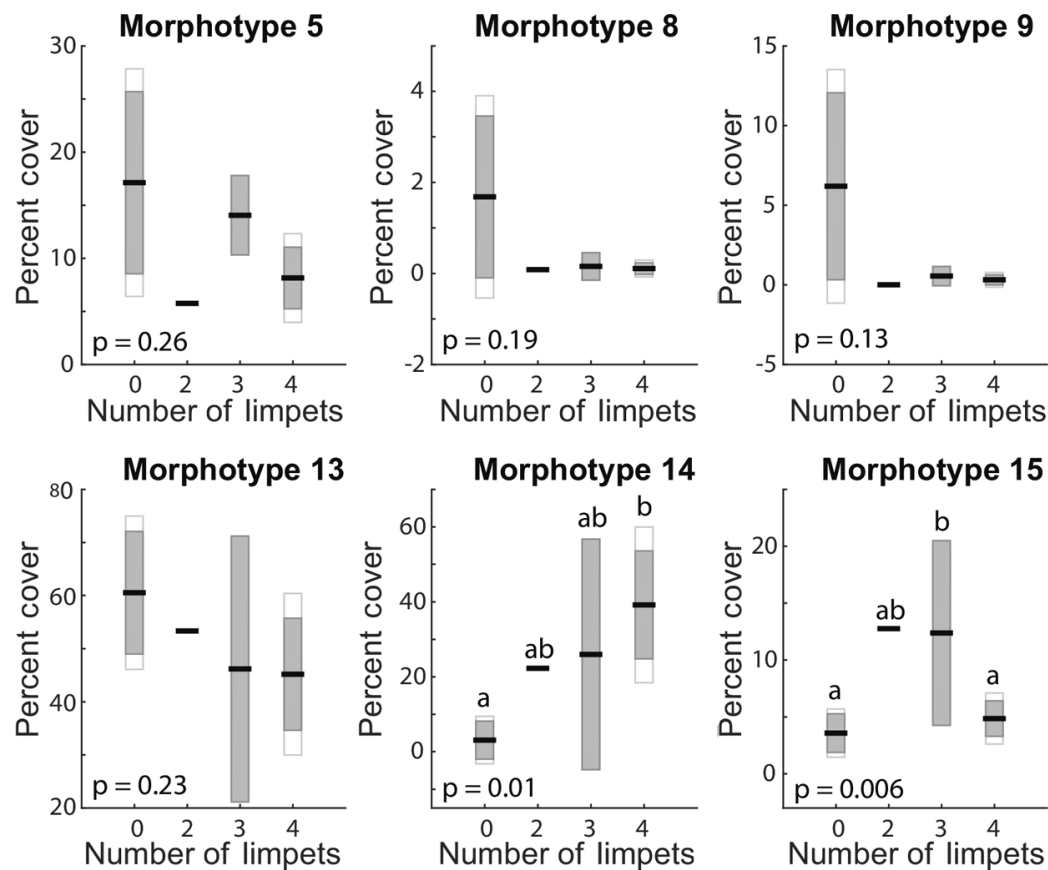

plates during the final month of each experiment $\left(F_{1,10}=5.57, \mathrm{p}=0.04\right.$ and $F_{1,17}=6.9, \mathrm{p}=0.012$, respectively). In 2013, increasing grazer density from approximately 250 limpets $\mathrm{m}^{-2}$ (2 limpets per plate) to 500 limpets $\mathrm{m}^{-2}$ (4 limpets per plate) resulted in a decrease in $F_{0}$ from $77.2(\mathrm{n}=1)$ to $48.1 \pm 2.0(\mathrm{n}=8)$. In 2014, increasing grazer density from approximately 125 limpets $\mathrm{m}^{-2}$ (1 limpet per plate) to 1000 limpets $\mathrm{m}^{-2}$ (8 limpets per plate) resulted in a decrease in $F_{0}$ from $82.7(n=1)$ to $17.8(n=1)$.

\section{DISCUSSION}

In the absence of limpet grazers, higher average maximum daily temperatures corresponded to lower $F_{0}$ values of the MPB. MPB is reduced in biomass and therefore less fluorescent when exposed to warm conditions (Jackson et al. 2010, Miller et al. 2015). However, limpet grazing reduced $F_{0}$ values to those typical of warm, ungrazed plates, regardless of temperature, suggesting that in intertidal regions where grazers are very sparse, $F_{0}$ values will be low if the region is warm, and high if the region is cool. The presence of grazers masks this signal, corroborating prior observations that limpet grazing suppresses natural variation in the density of the MPB along intertidal shores (Miller et al. 2015). Our results also indicate that a low $F_{0}$ value on a warm, ungrazed plate does not necessarily signify a change in assemblage structure at the microscopic level. However, a more extensive study designed to observe the composition of the MPB across a larger range of temperatures and with higher replication would better address this question.

\section{Dark-adapted fluorescence}

Dark-adapted fluorescence $\left(F_{0}\right)$, our proxy for chlorophyll a density within the MPB, was significantly higher on ungrazed plates than on grazed plates, indicating that intertidal grazers reduce the abundance of photosynthesizing organisms in the MPB. Due to our unreplicated experimental design, we could not directly test for an interaction between sites and grazing treatments when evaluating the effects of grazing on $F_{0}$ (Underwood 1997). However, we are reasonably confident that the observed effect is real. Factors strongly influencing $F_{0}$ values likely include tidal height, temperature and grazing intensity. Tidal height was held constant in our experiment, and we removed the significantly warmer site, site 6, from our analysis to try to control for spatial variation in temperature. After excluding this site, an interaction plot suggested no interactions between ungrazed and limpet-grazed treatments (Fig. S1 in the Supplement). Although ranks between limpetgrazed treatments varied from site to site, these interactions are not likely to be biologically significant because $F_{0}$ values varied between only 40 and 60, likely signifying very low food availability. 
The average grazed $F_{0}$ (mean $\left.\pm \mathrm{SE}=55.8 \pm 18.22\right)$ was much greater than the zero value obtained from new clean safety walk grip tape, suggesting that photosynthesizing organisms are still plentiful even under constant grazing pressure. Small organisms that limpets are unable to graze may be the primary contributors to this $F_{0}$ value, and it may represent a baseline signifying the limit to which grazers can deplete food resources. Herbivorous intertidal sea stars, in addition to a variety of gastropod grazers, have been found to have limited ability to deplete epilithic MPB, possibly because certain components are inaccessible, toxic or indigestible (Nicotri 1977, Underwood 1984a, Jackson et al. 2009). However, higher densities of L. scabra and L. austrodigitalis than our experimental density of about 500 limpets $\mathrm{m}^{-2}$ might graze down photosynthesizing organisms even further. Our data from 2014 indicated that densities of 1000 limpets $\mathrm{m}^{-2}$ should deplete $F_{0}$ to about half the level observed at 500 limpets $\mathrm{m}^{-2}$. However, this observation was based on data from a single plate. Excluding this sample, the negative correlation between limpet density and $F_{0}$ was not statistically significant; limpet densities between 125 and $500 \mathrm{~m}^{-2}$ grazed the MPB down to an average $F_{0}$ value of 44.5 \pm 0.9 . It is worth noting that all of these limpet densities have been observed at HMS. Although Morelissen \& Harley (2007) observed 515 L. scabra m ${ }^{-2}$ in limpet-rich regions of the intertidal zone at HMS, both L. scabra and L. austrodigitalis have clumpy distributions that can sometimes result in even higher local densities (D. LaScala-Gruenewald pers. obs.).

\section{Effects of grazers and grazer density}

The composition of grazed MPB was significantly different from that of ungrazed MPB. The limpetgrazed MPB contained fewer diatoms and filamentous cyanobacteria in particular, which may be the preferred food sources of Lottia spp. (Haven 1973, Nicotri 1977, Connor \& Quinn 1984, Hahn \& Denny 1989). On plates where fewer than 4 limpets grazed, there were higher percentages of coccoidal cyanobacteria, and lower percentages of encrusting organisms. This suggests an ordered grazing scheme, where filamentous cyanobacteria and diatoms are consumed first, followed by coccoidal cyanobacteria. This pattern may be due to animal preference (Schmitt 1996), but it is more likely due to topographical constraints. Lateral teeth in L. scabra and L. austrodigitalis are typically $100 \mu \mathrm{m}$ long and $50 \mu \mathrm{m}$ wide at the widest point, while tooth tips are typically sep- arated by distances of $100 \mu \mathrm{m}$ in the cross-radula direction and $200 \mu \mathrm{m}$ in the along-radula direction (D. LaScala-Gruenewald unpubl. data). In contrast, coccoidal cyanobacteria and some other organisms common on grazed plates (morphotypes 5 and 9 for example) are under $30 \mu \mathrm{m}$ in maximum dimension, and are possibly difficult to consume, especially if the substratum is rugose at the micrometer-scale.

Plates open to the natural suite of upper intertidal grazers had compositions that were intermediate between ungrazed and limpet-grazed plates. Although the number and species of grazers on the naturalgrazed plates were not monitored throughout the experiment, both Littorina spp. and Lottia spp. were capable of ascending the $12 \mathrm{~mm}$ plate edge (D. LaScala-Gruenewald pers. obs.), and the former were occasionally observed foraging on the plates during monthly surveys. Because no limpets were confined on the natural-grazed plates, they probably experienced reduced grazing pressure, resulting in higher percent cover of filamentous cyanobacteria and diatoms relative to the limpet-grazed plates. These results indicate that, at HMS, we should expect to see assemblages of primarily encrusting organisms where limpets are very dense, and assemblages of primarily filamentous cyanobacteria and diatoms in regions where limpets and other grazers are very sparse.

\section{Evidence for resource partitioning}

No significant differences were observed between the composition of the MPB grazed by L. scabra and that grazed by L. austrodigitalis. This result is consistent with previous findings (Haven 1973) indicating that these 2 species are in direct competition for food resources, and fails to support our hypothesis of complementarity. However, microscopic-level analyses of the MPB may be important in determining resource partitioning in other scenarios. L. scabra and $L$. austrodigitalis have very similar radula morphology; in fact, their radulae show only very subtle differences in lateral tooth shape, and in the length of their ribbon segments (Lindberg 1981, D. LaScalaGruenewald pers. obs.). Complementarity might still be observed if a wider array of grazers were considered. In particular, the abundant upper intertidal periwinkle, Littorina keenae, which was not included in this experiment, has distinctly different radula morphology, radula hardness, and feeding behavior, and may be able to access and consume components of the MPB that are unavailable to limpets (Goodwin \& Fish 1977, Hawkins et al. 1989). 


\section{Effects of grazing on nutrient ratios}

Limpet grazing also affected the $\mathrm{C}: \mathrm{N}$ ratio of the MPB. Cyanobacteria have been hypothesized to be nutritionally inferior to diatoms (Hargrave 1970, Nicotri 1977), and we found that the ratio of the percent cover of diatoms to the percent cover of cyanobacteria was significantly reduced in MPB grazed by L. scabra and $L$. austrodigitalis $\left(\mathrm{ANOVA}_{;} F_{3,20}=\right.$ 4.150, $\mathrm{p}=0.019$ ). L. scabra-grazed samples also had significantly increased $\mathrm{C}: \mathrm{N}$ ratios relative to ungrazed samples, indicating preferential consumption of high-nitrogen portions of the MPB. However, $L$. austrodigitalis-grazed samples had C:N ratios that were intermediate between L. scabra-grazed and ungrazed samples. Due to the relatively low number of limpet-grazed plates that had sufficient coverage of MPB to be used for the C:N analysis, we grouped plates foraged by 4,8 and twelve limpets, which raises the possibility that differences in $\mathrm{C}: \mathrm{N}$ ratios on limpet-grazed plates were driven by limpet density. The $L$. austrodigitalis-grazed plates suitable for C:N analysis were initially seeded with an average of 8.4 limpets while the L. scabra-grazed plates were seeded only with 4.4 limpets, but by the end of our study, the number of limpets on L. austrodigitalis and L. scabra-grazed plates were statistically indistinguishable (3.53 \pm 0.35$)$. This was likely due to the fact that $L$. austrodigitalis have a higher propensity for escaping our field enclosures than L. scabra (Miller et al. 2015). Additionally, no relationship was found between the number of limpets remaining on the plates at the end of the study and C:N ratio.

Prior research does not indicate that cyanobacteria have increased $\mathrm{C}: \mathrm{N}$ ratios relative to diatoms; both groups of organisms tend to have $\mathrm{C}: \mathrm{N}$ ratios between 3 and 30 (Brzezinski 1985, Fukuda et al. 1998, Geider \& La Roche 2002, Fu et al. 2007). However, C:N ratios are species- and location-specific, and vary with nutrient availability and physical parameters such as temperature (Geider \& La Roche 2002). More specific data on $\mathrm{C}: \mathrm{N}$ ratios of diatoms and cyanobacteria native to the upper intertidal zone at HMS would be necessary to better evaluate our hypothesis of depleted nutritional quality.

\section{Relevance and implications}

Our results corroborate previous work investigating potential partitioning of the MPB by intertidal gastropods. Nicotri (1977) showed that the limpets $L$. pelta, L. strigatella and L. scutum, in addition to the littorine snail L. scutulata, did not partition food resources at the microscopic scale. Similarly, Hawkins et al. (1989) examined 3 European gastropods, G. umbilicalis, L. littorea and P. vulgata, and found that their diets were indistinguishable despite differences in radula structure and feeding movements. The species in Nicotri's (1977) study occupy different microenvironments, and both studies considered some species that supplement the MPB in their diets with macroalgae. However, it appears that their results are generalizable to species that compete in the field for the entirety of their food resources. This is somewhat surprising: if food is limiting in the upper intertidal environment (Haven 1973, Branch \& Branch 1981, Underwood 1979, Underwood 1984a,b,c), there should be strong selective pressure favoring individuals who can partition the MPB. Nicotri suggests that the MPB may be too difficult to partition successfully, and the relative sizes of lateral teeth, ventral plates and maximum dimension of the components of the MPB considered here are consistent with that conclusion. However, Lottia spp. may still be partitioning resources with the littorine snails Littorina keenae, L. scutulata and L. plena, which graze on the MPB in the upper intertidal environment at HMS but have different radula structure. It would be interesting to observe whether the overlaps in diet reported by Nicotri (1977) and Hawkins et al. (1989) are also true for L. austrodigitalis, L. scabra and Littorina spp.

In general, we conclude that $L$. scabra and $L$. austrodigitalis are in direct competition for resources, and that their density affects the composition of the MPB. However, this conclusion has a number of caveats. First, although a large number of SEM images were taken for each treatment, the percent cover of each plate that was imaged was very small $(<1 \%)$. It is possible that the lack of significant differences between grazing treatments reported in our results was affected by low sampling area, although we doubt that our general conclusions would change given wider sampling. Additionally, we were unable to identify organisms to the species level. Again, doing so would be unlikely to change our general results, but more information might be provided by performing genomic analyses to determine the species involved.

Second, due to our unreplicated block experimental design, we were unable to test whether darkadapted fluorescence was influenced by an interaction between grazing treatment and site. A significant interaction between these 2 factors might point to an unmeasured spatial variable affecting 
dark-adapted fluorescence, such as temperature, which our analysis of covariance results suggest does affect $F_{0}$ values in concert with grazing treatment. A follow-up experiment with replication within sites would help elucidate this interaction. Additionally, because our experiment was not designed to test the relationship between numbers of limpet grazers and percent cover of morphotypes in the MPB, we were unable to determine how site and grazing treatment might affect our limpet density results. Our results suggest an ordered grazing scheme, where some morphotypes are removed before others; a follow-up experiment with appropriate replication manipulating these variables would further explore and validate this grazing pattern.

Finally, all of our experiments took place on rubber grip tape rather than the limpet's natural rock habitat. While this difference in substratum likely influenced the composition of both the ungrazed and grazed MPB, it allowed for consistency across sites and treatments. The native substratum at HMS is granite, an igneous rock containing feldspar, quartz and an array of other minerals that vary based on where and when the rock was formed. Each of these rock types has unique chemical and physical properties, which may affect patterns of growth in the MPB (Cattaneo-Vietti et al. 2002, Faimali et al. 2004, Perotti 2008). The granite at HMS is also topographically variable on scales ranging from meters to millimeters, and topography has been shown to influence the settlement and growth of MPB (Johnson 1994, Schmitt 1996, Keough et al. 1997, Hutchinson et al. 2006). Using rubber grip tape as the substratum for this experiment eliminated potential variability due to rock type and topography, which might otherwise have masked differences in the composition of the MPB due to grazing.

Rubber grip tape as an experimental substratum has some drawbacks. Although it is highly rugose across small scales, it does not mimic the larger (5-10 $\mathrm{mm})$ topographic features typical of the native granite substratum at HMS. Additionally, granite is much harder than rubber tape. Prior research has found that it takes less force to remove crustose algae from a harder surface (Padilla 1985), suggesting that limpets might feed more efficiently on a granite substratum. However, granite cannot be deformed by a radula, and limpets on granite may not be able to completely remove the MPB from small-scale topographical features. It is likely that both the rugosity and flexibility of rubber tape influenced the MPB composition observed on both grazed and ungrazed plates.
The deposition of pedal mucus by limpet grazers may also have had an effect on the compositions of the observed MPB. Limpet locomotion leaves behind a thin mucus layer that, in some species, has been shown to persist in the field and attract components of the MPB relative to adjacent mucus-free substratum (Davies \& Hawkins 1998). Connor \& Quinn (1984) and Connor (1986) examined the capacity for mucus from L. scabra and L. austrodigitalis to act as a persistent adhesive trap for components of the MPB. They found that mucus from both species does recruit components of the $\mathrm{MPB}$ at $+1.7 \mathrm{~m}$ above MLLW in the intertidal zone adjacent to Bodega Bay Marine Laboratory in Sonoma County, California, but mucus from L. scabra was more effective in doing so. Additionally, they found that the median persistence time for trails from both species in the field was 7 d. Research on another limpet species, Patella vulgata, indicated that its mucus was especially effective in trapping diatoms relative to other components of the MPB, and especially effective during the first $24 \mathrm{~h}$ after deposition (Davies et al. 1992). It is highly likely that our limpet-grazed plates were coated in pedal mucus throughout the duration of our field study, and that this mucus recruited additional MPB to grazed areas. However, the effects of this mucus were not sufficient to counter the effects of grazing. L. scabra and L. austrodigitalis-grazed plates showed statistically indistinguishable percentages of diatoms and cyanobacteria, and dark-adapted fluorescence. Additionally, L. scabra exhibited a significantly lower growth rate than $L$. austrodigitalis throughout the study, which fails to reflect a relative increase in food consumed (D. LaScala-Gruenewald unpubl. data). Differences in mucus properties between our study species were likely masked by grazing intensity. Both limpets cover an average area of about $50 \mathrm{~cm}^{2}$ during a foraging bout (D. LaScala-Gruenewald unpubl. data); the plate area $\left(78.54 \mathrm{~cm}^{2}\right)$ was too small to accommodate 4 limpets without regrazing.

The fact that L. scabra and L. austrodigitalis appear not to partition resources may have implications in the face of future climate change. Prior research indicates that moderate increases in temperature may create a temporary benefit for ectothermic organisms such as limpets (Miller et al. 2015). Increases in limpet growth rate have been observed at higher temperatures, and it has been hypothesized that either temperature effects on physiological processes or a shift towards consuming higher value food items may be mechanistically responsible (Miller et al. 2015). Our data indicate that the former is more likely, since the composition of MPB does not appear 
to vary across a small temperature range $\left(13-16^{\circ} \mathrm{C}\right)$. Provided that sufficient food resources are available, moderate increases in temperature during aerial exposure should result in increases in limpet metabolism and growth (Sanford 2002, Miller et al. 2015). However, our study also suggests that it may be possible for moderate densities of limpets $\left(200-500 \mathrm{~m}^{-2}\right)$ to reduce the MPB to a level where little or no food is available. Furthermore, the MPB that remains is of lower quality (i.e. higher C:N). Limpets under future climate change conditions may not be able to obtain sufficient resources at current spatial densities, and we may observe declines in densities of upper-intertidal limpets. We might also expect to see more success from organisms that do partition resources; complementarity has been documented between a number of intertidal organisms (e.g. Griffin et al. 2008, Byrnes \& Stachowicz 2009, Sanz-Lázaro et al. 2015) and is a leading explanation for how assemblages may cope with a changing climate (Loreau et al. 2001). Additionally, because increased temperatures correspond to decreases in $F_{0}$, less food may be available as the climate warms, particularly in the summer. The density and composition of the MPB vary seasonally (Underwood 1984b,c, Jackson et al. 2010), and our samples for this study were collected in December, when the MPB biomass was relatively high. As the MPB decreases over the summer months, there will be a corresponding decrease in food availability (Thompson et al. 2000). Individuals with limited access to resources are at greater risk of temperature stress, as they are less able to mitigate potential costs through physiological mechanisms such as the heat shock response (Fitzgerald-Dehoog et al. 2012).

Although L. scabra and L. austrodigitalis do not appear to partition resources at the microscopic level, the density of grazers does have an effect on the composition of the MPB. Both species consume large filamentous cyanobacteria and diatoms before eating the smaller filamentous and coccoidal cyanobacteria. Therefore, we should expect to see MPB relatively rich in filamentous cyanobacteria and diatoms in regions where limpets are sparse. It is also likely that small filamentous and coccoidal cyanobacteria form some baseline density of the MPB that is unavailable to upper intertidal grazers. Prior research suggests that differences in feeding behavior and radula morphology between limpet species may result in differing abilities to graze on certain species of macroalgae (Padilla 1985). Similarly, L. scabra and L. austrodigitalis may graze on certain morphotypes in the MPB first because of preference, or because of radula mor- phology and function. The microtopography of the substratum may also play a role. Hutchinson et al. (2006) examined the effects of substratum roughness on the composition of the MPB and molluscan grazing patterns using SEM. Diatoms were more abundant on rougher substrata, and both diatoms and filamentous cyanobacteria were more abundant around surface features. Finally, different species of molluscan grazers varied in their abilities to remove certain diatoms and cyanobacteria. It is likely that an interaction between grazing behavior, radula morphology and physical properties of the substratum (such as roughness and hardness) are responsible for our observed grazing patterns.

In summary, although the MPB contributes strongly to the primary productivity that fuels the upper intertidal ecosystem (Nicotri 1977, Underwood 1984a,b,c, Thompson et al. 2000), relatively few studies have considered the composition of intertidal MPB at the microscopic level (Hill \& Hawkins 1990, Nagarkar \& Williams 1997, Hutchinson et al. 2006), and even fewer have examined the impacts of environmental factors on the composition of the MPB (but see Nicotri 1977, Underwood 1984b, Thompson et al. 2004). Here, we found that 2 limpet species, L. scabra and $L$. austrodigitalis, appear to compete directly for food resources even at the microscopic scale, and that grazer density influences the composition of the MPB. C:N ratios on grazed and ungrazed plates suggest that limpet grazing may reduce the nutritional content of the MPB via selective consumption of high-N organisms. Additionally, we found that moderate increases in temperature decreased the density of the MPB, but did not change its composition. As the climate continues to warm, we expect to see decreases in the density of the MPB and consequent decreases in grazer density, especially among species that do not partition resources at the microscopic level.

Acknowledgements. We thank G. Bernatchez for assistance with elemental analyses and E. Duncan, F. King, J. McNamara, B. Pagan and C. Prince for assistance in setting up and maintaining the experiment in the field. This work was funded by NSF grants OCE-1131038 and 1130095 to B.J.A. and M.W.D., respectively, and by contribution 467 from PISCO, the Partnership for Interdisciplinary Studies of Coastal Oceans.

\section{LITERATURE CITED}

Barranguet C, Kromkamp J, Peene J (1998) Factors controlling primary production and photosynthetic characteristics of intertidal microphytobenthos. Mar Ecol Prog Ser 173:117-126 
Best RJ, Chaudoin AL, Bracken MES, Graham MH, Stachowicz JJ (2014) Plant-animal diversity relationships in a rocky intertidal system depend on invertebrate body size and algal cover. Ecology 95:1308-1322

> Bracken MES, Low NHN (2012) Realistic losses of rare species disproportionately impact higher trophic levels. Ecol Lett 15:461-467

- Bracken MES, Williams SL (2013) Realistic changes in seaweed biodiversity affect multiple ecosystem functions on a rocky shore. Ecology 94:1944-1954

Bracken MES, Jones E, Williams SL (2011) Herbivores, tidal elevation, and species richness simultaneously mediate nitrate uptake by seaweed assemblages. Ecology 92: 1083-1093

Bracken MES, Dolecal RE, Long JD (2014) Community context mediates the top-down vs. bottom-up effects of grazers on rocky shores. Ecology 95:1458-1463

Branch G, Branch M (1981) The living shores of Southern Africa. C. Struik, Cape Town, South Africa

$>$ Brzezinski MA (1985) The Si:C:N ratio of marine diatoms: interspecific variability and the effect of some environmental variables. J Phycol 21:347-357

- Byrnes JE, Stachowicz J (2009) The consequences of consumer diversity loss: Different answers from different experimental designs. Ecology 90:2879-2888

- Byrnes J, Stachowicz JJ, Hultgren KM, Hughes RA, Olyarnik SV, Thornber CS (2006) Predator diversity strengthens trophic cascades in kelp forests by modifying herbivore behaviour. Ecol Lett 9:61-71

Cardinale BJ, Wright JP, Cadotte MW, Carroll IT and others (2007) Impacts of plant diversity on biomass production increase through time because of species complementarity. Proc Natl Acad Sci USA 104:18123-18128

Cardinale BJ, Matulich KL, Hooper DU, Byrnes JE and others (2011) The functional role of producer diversity in ecosystems. Am J Bot 98:572-592

Castenholz RW (1961) Effect of grazing on marine littoral diatom populations. Ecology 42:783-794

Cattaneo-Vietti R, Albertelli G, Bavestrello G, Bianchi CN and others (2002) Can rock composition affect sublittoral epibenthic communities? Mar Ecol 23:65-77

Clarke KR, Warwick RM (2001) Change in marine communities: An approach to statistical analysis and interpretation, 2nd edition. PRIMER-E, Plymouth, MA

- Coleman RA, Underwood AJ, Benedetti-Cecchi L, Aberg P and others (2006) A continental scale evaluation of the role of limpet grazing on rocky shores. Oecologia 147: 556-564

Collins LS (1976) Abundance, substrate angle, and desiccation resistance in two sympatric species of limpets. Veliger 19:199-203

- Connor VM (1986) The use of mucous trails by intertidal limpets to enhance food resources. Biol Bull 171:548-564

Connor VM, Quinn JF (1984) Stimulation of food species growth by limpet mucus. Science 225:843-844

$>$ Crummett LT, Eernisse DJ (2007) Genetic evidence for the cryptic species pair, Lottia digitalis and Lottia austrodigitalis and microhabitat partitioning in sympatry. Mar Biol 152:1-13

> Davey ME, O'Toole GA (2000) Microbial biofilms: from ecology to molecular genetics. Microbiol Molec Biol Rev 64: 847-867

Davies MS, Hawkins SJ (1998) Mucus from marine molluscs. Adv Mar Biol 34:1-71

> Davies MS, Hawkins SJ, Jones HD (1992) Pedal mucus and its influence on the microbial food supply of two intertidal gastropods, Patella vulgata L. and Littorina littorea (L.). J Exp Mar Biol Ecol 161:57-77

> Dayton PK (1975) Experimental evaluation of ecological dominance in a rocky intertidal algal community. Ecol Monogr 45:137-159

> Della Santina P, Sonni C, Sartoni G, Chelazzi G (1993) Food availability and diet composition of three coexisting Mediterranean limpets (Patella spp.). Mar Biol 116:87-95

$>$ Dong Y, Somero GN (2009) Temperature adaptation of cytosolic malate dehydrogenases of limpets (genus Lottia): differences in stability and function due to minor changes in sequence correlate with biogeographic and vertical distributions. J Exp Biol 212:169-177

$>$ Dong Y, Miller LP, Sanders JONG, Somero GN (2008) Heatshock protein 70 (Hsp70) expression in four limpets of the genus Lottia: Interspecific variation in constitutive and inducible synthesis correlates with in situ exposure to heat stress. Biol Bull 215:173-181

Faimali M, Garaventa F, Terlizzi A, Chiantore M, CattaneoVietti R (2004) The interplay of substrate nature and biofilm formation in regulating Balanus amphitrite Darwin, 1854 larval settlement. J Exp Mar Biol Ecol 306:37-50

Fargione JE, Tilman D (2005) Diversity decreases invasion via both sampling and complementarity effects. Ecol Lett 8:604-611

Fitzgerald-Dehoog L, Browning J, Allen BJ (2012) Food and heat stress in the California mussel: evidence for an energetic trade-off between survival and growth. Biol Bull 223:205-216

Fu FX, Warner ME, Zhang Y, Feng Y, Hutchins DA (2007) Effects of increased temperature and $\mathrm{CO}_{2}$ on photosynthesis, growth, and elemental ratios in marine Synechococcus and Prochlorococcus (Cyanobacteria). J Phycol 43:485-496

Fukuda R, Ogawa H, Nagata T (1998) Direct determination of carbon and nitrogen contents of natural bacterial assemblages in marine environments. Appl Environ Microbiol 64:3352-3358

Gee J, Warwick R (1994) Metazoan community structure in relation to the fractal dimensions of marine macroalgae. Mar Ecol Prog Ser 103:141-150

Geider R, La Roche J (2002) Redfield revisited: variability of $\mathrm{C}: \mathrm{N}: \mathrm{P}$ in marine microalgae and its biochemical basis. Eur J Phycol 37:1-17

Goodwin BJ, Fish JD (1977) Inter- and intraspecific variation in Littorina obtusata and L. mariae. J Molluscan Stud 43: 241-254

Griffin JN, de la Haye K, Hawkins SJ, Thompson RC, Jenkins SR (2008) Predatory diversity and ecosystem functioning: Density modifies the effect of resource partitioning. Ecology 89:298-305

> Hahn T, Denny M (1989) Tenacity-mediated selective predation by oystercatchers on intertidal limpets and its role in maintaining habitat partitioning by 'Collisella' scabra and Lottia digitalis. Mar Ecol Prog Ser 53:1-10

Hargrave BT (1970) The utilization of benthic microflora by Hyalella azteca (Amphipoda). J Anim Ecol 39:427-437

Harper JL (1977) Population biology of plants. The Blackburn Press, Caldwell, NJ

> Haven SB (1973) Competition for food between the intertidal gastropods Acmaea scabra and Acmaea digitalis. Ecology 54:143-151

- Hawkins SJ, Watson DC, Hill AS, Harding SP, Kyriakides MA, Hutchinson S, Norton TA (1989) A comparison of 
feeding mechanisms in microphagous, herbivorous, intertidal, prosobranchs in relation to resource partitioning. J Molluscan Stud 55:151-165

> Hector A, Schmid B, Beierkuhnlein C, Caldeira MC, and others (1999) Plant diversity and productivity experiments in european grasslands. Science 286:1123-1127

Hill AS, Hawkins SJ (1990) An investigation of methods for sampling microbial films on rocky shores. J Mar Biol Assoc UK 70:77-88

> Honeywill C, Paterson D, Hagerthey S (2002) Determination of microphytobenthic biomass using pulse-amplitude modulated minimum fluorescence. Eur J Phycol 37: 485-492

> Hooper DU, Chapin FS III, Ewel JJ, Hector A and others (2005) Effects of biodiversity on ecosystem functioning: a consensus of current knowledge. Ecol Monogr 75:3-35

> Hutchinson N, Nagarkar S, Aitchison JC, Williams GA (2006) Microspatial variation in marine biofilm abundance on intertidal rock surfaces. Aquat Microb Ecol 42: 187-197

Ives AR, Cardinale BJ, Snyder WE (2004) A synthesis of subdisciplines: Predator-prey interactions, and biodiversity and ecosystem functioning. Ecol Lett 8:102-116

> Jackson AC, Murphy RJ, Underwood AJ (2009) Patiriella exigua: grazing by a starfish in an overgrazed intertidal system. Mar Ecol Prog Ser 376:153-163

> Jackson AC, Underwood AJ, Murphy RJ, Skilleter GA (2010) Latitudinal and environmental patterns in abundance and composition of epilithic microphytobenthos. Mar Ecol Prog Ser 417:27-38

> Johnson LE (1994) Enhanced settlement on microtopographical high points by the intertidal red alga Halosaccion glandiforme. Limnol Oceanogr 39:1893-1902

Keough MJ, Quinn GP, Bathgate R (1997) Geographic variation in interactions between size classes of the limpet Cellana tramoserica. J Exp Mar Biol Ecol 215:19-34

Levine JM, D'Antonio CM (1999) Elton revisited: a review of evidence linking diversity and invisibility. Oikos 87: 15-26

Lindberg DR (1981) Invertebrates of the San Francisco Bay estuary system. The Boxwood Press, Pacific Grove, CA

Littler MM, Littler DS (1984) Relationships between macroalgal functional form groups and substrata stability in a subtropical rocky-intertidal system. J Exp Mar Biol Ecol 74:13-34

> Loreau M, Naeem S, Inchausti P, Bengtsson J and others (2001) Biodiversity and ecosystem functioning: current knowledge and future challenges. Science 294:804-808

MacArthur RH, Pianka ER (1966) On optimal use of a patchy environment. Am Nat 100:603-609

> Maggi E, Jackson AC, Tolhurst TJ, Underwood AJ, Chapman MG (2013) Changes in microphytobenthos fluorescence over a tidal cycle: implications for sampling designs. Hydrobiologia 701:301-312

> McNaughton SJ (1977) Diversity and stability of ecological communities: a comment on the role of empiricism in ecology. Am Nat 111:515-525

> Miller LP, Allen BJ, King FA, Chilin DR, Reynoso VM, Denny MW (2015) Warm microhabitats drive both increased respiration and growth rates of intertidal consumers. Mar Ecol Prog Ser 522:127-143

Morelissen B, Harley CDG (2007) The effects of temperature on producers, consumers, and plant-herbivore interactions in an intertidal community. J Exp Mar Biol Ecol 348: 162-173
Naeem S (2002) Ecosystem consequences of biodiversity loss: the evolution of a paradigm. Ecology 83:1537-1552

Naeem S, Thompson LJ, Lawler SP, Lawton JH, Woodfin RM (1994) Declining biodiversity can alter the performance of ecosystems. Nature 368:734-737

Nagarkar S, Williams GA (1997) Comparative techniques to quantify cyanobacteria dominated epilithic biofilms on tropical rocky shores. Mar Ecol Prog Ser 154:281-291

> Nicotri ME (1977) Grazing effects of four marine intertidal herbivores on the microflora. Ecology 58:1020-1032

Nielsen KJ (2001) Bottom-up and top-down forces in tide pools: test of a food chain model in an intertidal community. Ecol Monogr 71:187-217

Padilla DK (1985) Structural resistance of algae to herbivores - a biomechanical approach. Mar Biol 90:103-109

Pedersen MF, Borum J (1996) Nutrient control of algal growth in estuarine waters: nutrient limitation and the importance of nitrogen requirements and nitrogen storage among phytoplankton and species of macroalgae. Mar Ecol Prog Ser 142:261-272

Perotti EA (2008) Does geology matter? The effects of substratum and substrate properties on temperate rocky intertidal communities. Doctoral thesis, University of California, Berkeley

Poore AGB, Campbell AH, Coleman RA, Edgar GJ and others (2012) Global patterns in the impact of marine herbivores on benthic primary producers. Ecol Lett 15: 912-922

R Development Core Team (2016) R: a language and environment for statistical computing. R Foundation for Statistical Computing, Vienna. www.R-project.org/

Ricketts E, Calvin J, Hedgpeth JW (1968) Between Pacific tides. Stanford University Press, Stanford, CA

Sanford E (2002) The feeding, growth, and energetics of two rocky intertidal predators (Pisaster ochraceus and Nucella canaliculata) under water temperatures simulating episodic upwelling. J Exp Mar Biol Ecol 273:199-218

> Sanz-Lázaro C, Rindi L, Maggi E, Dal Bello M, BenedettiCecchi L (2015) Effects of grazer diversity on marine microphytobenthic biofilm: a 'tug of war' between complementarity and competition. Mar Ecol Prog Ser 540: 145-155

- Schmitt RJ (1996) Exploitation competition in mobile grazers: trade-offs in use of a limited resource. Ecology 77:408-425

> Sekar R, Venugopalan VP, Satpathy KK, Nair KVK, Rao VNR (2004) Laboratory studies on adhesion of microalgae to hard substrates. Hydrobiologia 512:109-116

> Serôdio J, Vieira S, Cruz S (2008) Photosynthetic activity, photoprotection and photoinhibition in intertidal microphytobenthos as studied in situ using variable chlorophyll fluorescence. Cont Shelf Res 28:1363-1375

Seuront L, Duponchel AC, Chapperon C (2007) Heavytailed distributions in the intermittent motion behaviour of the intertidal gastropod Littorina littorea. Physica A 385:573-582

> Sommer U (2001) Reversal of density dependence of juvenile Littorina littorea (Gastropoda) growth in response to periphyton nutrient status. J Sea Res 45:95-103

Tahvanainen JO, Root RB (1972) The influence of vegetational diversity on the population ecology of a specialized herbivore, Phyllotreta cruciferae (Coleoptera: Chrysomelidae). Oecologia 10:321-346

Thompson RC, Roberts MF, Norton TA, Hawkins SJ (2000) Feast or famine for intertidal grazing molluscs: a mismatch between seasonal variations in grazing intensity 
and the abundance of microbial resources. Hydrobiologia 440:357-367

Thompson RC, Norton TA, Hawkins SJ (2004) Physical stress and biological control regulate the balance between producers and consumers in marine intertidal biofilms. Ecology 85:1372-1382

Tilman D (1988) Plant strategies and the dynamics and structure of plant communities. Princeton University Press, Princeton, NJ

Tilman D (2000) Causes, consequences and ethics of biodiversity. Nature 405:208-211

Tilman D, Wedin D, Knops J (1996) Productivity and sustainability influenced by biodiversity in grassland ecosystems. Nature 379:718-720

Underwood AJ (1979) The ecology of intertidal gastropods. Adv Mar Biol 16:111-210

Underwood AJ (1984a) Microalgal food and the growth of the intertidal gastropods Nerita atramentosa (Reeve) and Bembicium nanum (Lamarck) at four heights on a shore. J Exp Mar Biol Ecol 79:277-291

Editorial responsibility: Antony Underwood, Sydney, New South Wales, Australia
Underwood AJ (1984b) The vertical distribution and seasonal abundance of intertidal microalgae on a rocky shore in New South Wales. J Exp Mar Biol Ecol 78: $199-220$

Underwood AJ (1984c) Vertical and seasonal patterns in competition for microalgae between intertidal gastropods. Oecologia 64:211-222

Underwood AJ (1997) Experiments in ecology. Cambridge University Press, Cambridge

Underwood AJ, Murphy RJ (2008) Unexpected patterns of facilitatory grazing revealed by quantitative imaging. Mar Ecol Prog Ser 358:85-94

Wahl M (1989) Marine epibiosis. I. Fouling and antifouling: some basic aspects. Mar Ecol Prog Ser 58:175-189

- Williams SL, Bracken MES, Jones E (2013) Additive effects of physical stress and herbivores on intertidal seaweed biodiversity. Ecology 94:1089-1101

Wolcott TG (1973) Physiological ecology and intertidal zonation in limpets (Acmaea): a critical look at 'limiting factors.' Biol Bull 145:389-422

Submitted: November 18, 2015; Accepted: May 13, 2016

Proofs received from author(s): July 1, 2016 